\title{
Simmel e a hipótese da compreensão como reconstrução de processos psíquicos no conhecimento histórico
}

\author{
Simmel and the hypothesis of comprehension as reconstruction of
} psychic processes in historical knowledge

Marcos César Seneda ${ }^{1}$

\begin{abstract}
Resumo: Esse texto procura explicitar a tese da compreensão atual que Simmel pressupõe como lócus de apreensão e interpretação dos processos humanos dotados de sentido. Para explicitá-la, confronta as posições de Dilthey e Simmel sobre o papel da vivência na fundamentação do conhecimento histórico. Ao contrário de Dilthey, no entanto, Simmel não pressupõe uma vivência que possa ser apreendida em outrem ou circunscrita a partir de um objeto, porque põe o fundamento da compreensão na atualidade daquele que compreende. Assim, opera com possibilidades objetivas da construção de conexões de sentido por meio da projeção de processos psíquicos. Conquanto dificilmente seja lembrado no debate sobre a compreensão ou sobre a filosofia da história, Simmel possui uma posição própria e consistente acerca da fundamentação do conhecimento histórico, que pode ou abrir novos ângulos de pesquisa ou ser fecunda para se reexaminar perspectivas já consolidadas.
\end{abstract}

Palavras-chave: Compreensão. Dilthey. Rickert. Simmel. Vivência.

\begin{abstract}
This text seeks to clarify the thesis of the current understanding that Simmel presupposes as the locus of comprehension and interpretation of human processes endowed with meaning. In order to clarify this, the positions of Dilthey and Simmel are compared regarding the role that the lived experience plays in the founding of historical knowledge. In contrast to Dilthey, however, Simmel does not presuppose a lived experience that could be understood in another person or circumscribed as based on an object, because he places the foundation of understanding in the present state of the one who understands. Thus, he operates with objective possibilities of the construction of connections of meaning by means of the projection of psychic processes. Although he hardly is remembered in the debate regarding interpretation or regarding the philosophy of history, Simmel has his own consistent position concerning the founding of historical knowledge which may either open new directions of research or be fruitful for reexamining already consolidated perspectives.
\end{abstract}

Key words: Dilthey. Lived experience. Rickert. Simmel. Understanding.

\section{O psíquico como possibilidade da síntese histórica}

Em Kant não há, como em Dilthey, uma cisão da experiência em dois loci que poderíamos denominar experiência objetiva (Erfahrung) e

\footnotetext{
${ }^{1}$ Professor do Programa de Pós-Graduação em Filosofia e do Curso de Graduação em Filosofia, e Professor Associado do Instituto de Filosofia (IFILO) da Universidade Federal de Uberlândia (UFU), Uberlândia (MG), Brasil.
} 
experiência vivida (Erlebnis). Assim, conquanto haja em Kant, por um lado, uma teoria cosmopolita da história, que procura posicionar o telos da ação humana a partir de seus aspectos políticos, jurídicos e éticos, não há em Kant, por outro lado, uma teoria sobre a especificidade da compreensão histórica. Na Alemanha, o edifício da crítica kantiana confinava um homem que ainda não fora ocupado pela dimensão compreensiva, conforme descrita por Dilthey, e uma crítica da razão histórica apresentava-se como uma meta no horizonte tanto de historicistas como de neo-kantianos. Embora não seja um pensador de fácil enquadramento, também Georg Simmel percorreu os corredores dessa crítica. Seu livro - Os problemas da filosofia da história ${ }^{2}$-, já em seu prefácio, é aberto em um fecundo e direto debate com Kant.

Simmel já parte do problema compreensivo, demarcando-o com a questão que em Kant sempre abre a fundamentação: como é possível a história? (SIMMEL, 1997, IX: 229). E de princípio Simmel indica tal possibilidade pela capacidade do espírito de construir e se orientar em meio a uma totalidade, que sempre é reivindicada, por exemplo, para se unificar uma série de ações, ou para reconstruir a coerência que pressupomos em um interlocutor, ou para dar significado a uma sequência de relatos, quadros, cartas, etc. Este processo nos é apresentado por Simmel como um a priori, dado na capacidade que possuímos de valorar e reproduzir hipotéticas sequências de representações, descritivas de um virtual estado psíquico. Assim o demarca: "nesse sentido, é uma proposição a priori que a alma (die Seele) de um outro seja para nós uma unidade, isto é, que ela apresente uma conexão compreensível de processos, e conhecemos tal conexão por meio desses processos ou pelos processos como tais” (SIMMEL, 1997, IX: 241). Por certo que não há ponto de partida mais circunscrito ao indivíduo que o psíquico. Mas do psíquico Simmel quer reter mais acentuadamente a forma pela qual conexões

\footnotetext{
${ }^{2}$ Este texto recebeu três edições durante a vida de Simmel. A primeira, de 109 p., é de 1892; a segunda, de 1905, expandida para 169 p., retoma, desenvolve e complementa muitos dos temas elaborados na primeira edição. A terceira, de 1907, apresenta algumas variantes em relação ao texto da segunda edição. O texto aqui utilizado corresponde ao da terceira edição, bastante ampliada e modificada pelo autor, a saber: SIMMEL, Georg. Die Probleme der Geschichtsphilosophie: Eine erkenntnistheoretische Studie. Dritte, erweiterte Auflage, Leipzig: Verlag von Duncker \& Humblot, 1907, XII, 179 S. Esse texto é aqui citado a partir da seguinte edição: SIMMEL, Georg. Die Probleme der Geschichtsphilosophie: Eine erkenntnistheoretische Studie. In: Gesamtausgabe. Frankfurt am Main: Suhrkamp, 1997. Bd. IX. As referências serão assinaladas do seguinte modo: o número em romano indica o volume, seguido do número da página respectiva. Embora tenha sido consultada a edição francesa (SIMMEL, 1984), todas as citações foram traduzidas diretamente do original alemão (SIMMEL, 1997).
} 
compreensíveis são construídas para embutir intencionalidade nos fatos observáveis. Por isso postula a unidade interna da personalidade como princípio de construção dessas conexões. A personalidade seria essa conformação onde o psíquico sobressairia como instância do sentido, assim distinguindo-se do meramente orgânico. Simmel torna essa questão mais clara com o exemplo da testemunha ocular:

ainda que com o melhor empenho de se ater à verdade, o narrador acrescenta elos (Glieder) ao imediatamente ocorrido, que completam o acontecimento no sentido da leitura que ele extraiu do dado efetivamente (aus dem wirklich Gegebenen) [...] (SIMMEL, 1997, IX: 241)

Desse modo, o acontecimento nunca está disponível objetivamente, porque ele precisa ser composto por partes percorridas pelo sentido. Sua dimensão também nunca está delimitada objetivamente, porque a capacidade de atribuir sentido pode ou expandir a sequência dos fatos conectáveis ou aumentar os elos de interconexão. Logo, o lócus do psíquico precede a história do ponto de vista da compreensão, porque a história é, analogicamente, produto de testemunhas oculares, que a todo o momento procuram dar significação aos dados observáveis ${ }^{3}$. Essa analogia pode indicar o deslocamento interpretativo em questão. Como o foco de Simmel são as conexões vividas daquele que procura construir a compreensão histórica, trata-se sempre de reviver supostas conexões psíquicas que formariam a sequência significativa de um relato histórico. Em Simmel,

\footnotetext{
${ }^{3}$ Simmel afirma: "assim como nós compreendemos (verstehen) o interior (das Innere) por analogia com o exterior, [...] do mesmo modo nós compreendemos o que o ser humano exterioriza (das Äussere der Menschen) somente pela suposição de estados interiores (Innerlichkeiten)" (SIMMEL, 1997, IX: 239). Em outra passagem, comentando o caso da testemunha ocular e similares, argumenta que as suposições completam os acontecimentos externos na medida em que "[...] produzem uma série ininterrupta paralela aos processos internos (SIMMEL, 1997, IX: 242). Simmel enfoca, portanto, a capacidade do observador de se apropriar de dados observáveis e conferir-lhes sequências, interconexões e sentidos, tornando possível a sua apreensão enquanto acontecimento. Essa capacidade do observador de, a partir da sincronia, intervir na diacronia dos dados causais, está bem explicitada por K. Lichtblau (1994, p. 6184). Em um artigo dedicado ao tema, o autor comenta: "rejeitando todas as reificações 'realistas' ou 'naturalistas' das formações de conceitos 'típico-ideais', Simmel foi, portanto, não menos rigoroso do que Max Weber. Ao contrário de Weber, ele adicionalmente quase chega a dissolver as sucessões 'externas' que constituem o mundo empírico dos fenômenos em uma certa simultaneidade ou atemporalidade da 'contemplação interna' (goes so far as to dissolve the 'external' successions within the empirical world of phenomena into a simultaneity or timelessness of 'inner contemplation). Mesmo a assim chamada 'interpretação histórica' é, por conseguinte, somente a expressão de um processo lógico para Simmel, no qual a diferença entre ego e não-ego, sujeito e objeto, assim como presente e passado é primeiro constituída" (K. LICHTBLAU, 1994, p. 72). Este comentário também explicita de modo bastante lúcido uma diferença capital dos métodos empregados por Simmel e Weber. Simmel sempre enfatiza a capacidade da subjetividade de atribuir significações às possibilidades que são produzidas a partir dos dados objetivos. Weber sempre ressalta as possibilidades objetivas, que delimitam e condicionam as possibilidades empíricas da interpretação.
} 
portanto, a interpretação percorre um trajeto inverso ao pressuposto em Dilthey: não se trata de partir de uma exteriorização para penetrar em uma vivência, mas justamente de trazer os dados observáveis, sejam eles produtos da natureza ou da intervenção do homem, para dentro de uma atualidade vivida que lhes confere uma significação. Em Dilthey havia a possibilidade de o trajeto compreensivo estender-se em duas direções: podia-se ir tanto da vivência à exteriorização quanto da exteriorização à vivência. Desse modo, tanto um poeta podia exteriorizar sua vivência em versos como um leitor poderia, a partir desses versos, penetrar na vivência que lhes deu origem. Em Simmel, esta objetividade sempre estará restringida pela subjetividade, porque a compreensão sempre está em si referenciada, ou seja, ela sempre ocorrerá a partir da vivência atual daquele que compreende. Ou seja, Dilthey sustenta que a interioridade vivida é dotada de tal unidade e imediatidade que ela sempre se conjuga às obras e produções que elabora, enquanto Simmel defende que essa interioridade pertence mormente à posição atual daquele que compreende 4 .

Está posto o problema da objetividade. E em Simmel com acentuado cunho de irracionalidade, porque torna-se difícil determinar a base objetiva que sustenta o conhecimento histórico. Como Simmel pressupõe que os dados observáveis precisam se tornar objetos históricos a partir de uma unificação cognitiva ${ }^{5}$ construída pelo observador, ele subtrai qualquer semântica prévia aos dados observáveis que deveria

\footnotetext{
${ }^{4}$ Essa distância entre os procedimentos metodológicos de cada autor também pode ser encontrada nos dois seguintes comentários de B. Schwartz. O autor afirma que "Dilthey acreditava que somente um conceito pode produzir cientificamente compreensão social, e esse é o conceito de intuição, que dá acesso à natureza interna do sujeito. $\mathrm{O}$ observador intuitivo re-experimenta em sua própria consciência as experiências de outros” (B. SCHWARTZ, 2017, p. 217). Em relação a Simmel, afirma que "observadores obtêm informações de seus sujeitos entrando em empatia com eles, evocando inferencialmente em si próprios os pensamentos e sentimentos que eles pensariam e sentiriam [se estivessem] no lugar de seus sujeitos. A validade de todas as avaliações empáticas, no entanto, é parcial e varia de caso a caso" (B. SCHWARTZ, 2017, p. 225). Pensamos que essa diferença metodológica é muito importante para separar as propostas cognitivas dos dois autores. Dilthey sempre pressupõe uma unidade da vivência que está ao alcance do intérprete, enquanto Simmel propõe que o observador transforme o seu ato psíquico em um experimento para tentar alcançar em si o que se teria passado na vivência alheia. Esse futuro do pretérito - "o que se teria passado" - explicita bem os limites com os quais Simmel restringe o alcance do método empático.

${ }^{5}$ Simmel argumenta: "mas um historicismo de cunho empirista julga sempre poder ainda alcançar aquelas conexões mediante a simples consideração da 'realidade histórica' em si própria, as quais já se precisa ter para que a realidade torne-se para nós uma realidade histórica como tal” (SIMMEL, 1997, IX: 262). Para retratar essa polimorfa construção da unidade, Simmel alude à história da arte e comenta como a apreensão do movimento, da perspectiva, das formas, etc. nos permite delimitar uma época histórica e compreendê-la pela contraposição a outras. Isso nos mostra que a sociologia da arte (F. Dörr-Backes, 1995, p. 121) também é um elemento importante para se avaliar as teses de Simmel acerca da epistemologia da história e da sociologia compreensiva concebida como uma filosofia da vida social.
} 
pertencer-lhes objetivamente. Nesse sentido, Simmel critica o historicismo, porque ele pressupõe uma teoria realista da história, ou seja, o historicismo postula que o significado da ação humana já estaria presente no suposto substrato da realidade histórica, isto é, o historicismo constrói a separação entre natureza e história a partir do pressuposto de que todos os elementos de um tempo histórico estão inscritos nos produtos das ações humanas. O obstáculo a ser transposto, então, é a decifração desse tempo histórico alojado nos produtos das ações humanas. Há, contudo, em Simmel, uma transposição das dificuldades, porque agora a significação do objeto histórico é transferida do suposto substrato histórico para o interior do ato psíquico.

\section{A crítica à teoria "realista" da história}

O livro de Simmel - Os problemas da filosofia da história ${ }^{6}$ - é percorrido pela crítica ao realismo ingênuo. Este realismo ingênuo poderia ser entendido a partir da concepção da teoria da verdade como mera cópia da realidade, cujo objetivo seria estabelecer uma correspondência entre o suposto real e sua representação cognitiva. Se transposto para o quadro do pensamento kantiano, trata-se de um problema de difícil formulação e de difícil solução, porque em sua base nos deparamos com a seguinte questão fundamental: o que sintetiza a apresentação dos dados observáveis e o que unifica sua apreensão? Simmel formula a crítica desse problema sob pelo menos três ângulos diferentes, mas sua crítica alcança procedimentos muito mais elaborados do que os empregados pelo mero realismo ingênuo, conforme veremos a seguir.

A primeira formulação retoma esse problema no interior da teoria das ciências naturais. Simmel afirma que as ciências naturais já tinham abandonado o realismo cognitivo, que "[...] explica a verdade pela concordância do pensamento (no sentido da imagem em um espelho) com aquilo que para ele é o objeto externo em sentido absoluto [...]” (SIMMEL, 1997, IX: 275-276). Seu principal pressuposto é o de que todos os elementos de uma realidade podem ser apreendidos objetivamente no

\footnotetext{
${ }^{6} \mathrm{O}$ título pode gerar equívocos, uma vez que não se trata da disciplina Filosofia da História como hoje a conhecemos, ou seja, como a investigação metafísica do sentido subjacente à diacronia construída pelas ações humanas. Simmel propõe aqui esta disciplina como uma meta-teoria da história entendida como ciência empírica, ou seja, como uma investigação do fundamento cognitivo que possibilita compreender o sentido singular do agir humano.
} 
quadro das representações elaboradas por uma teoria, ou seja, de que há uma apreensão direta da realidade pelas formas cognitivas. Esta formulação põe em jogo várias dificuldades. A primeira seria entender o sentido em que algo pode ser concebido como exterior ao observador. Este problema já principia rigorosamente com Kant, que separa fenômeno e coisa em si, projetando o domínio teórico cognoscível inteiramente no interior da sensibilidade do sujeito cognoscente. Kant afirma que o nosso interesse cognitivo deve se dirigir não ao mundo dado, mas sim ao mundo aberto no tempo e no espaço, o qual é preenchido pelos conteúdos da nossa intuição empírica. Se Kant já havia rompido com a tese do realismo ingênuo, que pressupõe o conhecimento como cópia mecânica do mundo externo, esta concepção, por sua vez, sobreviveu longamente na teoria da ciência. Simmel, no entanto, com dois fatos básicos, o da modelização e o da utilização da matemática para apreender componentes específicos dos fenômenos observáveis, sustenta que no próprio ofício do cientista esta concepção já tinha se tornado ultrapassada7 .

Mas sua crítica dirige-se também, em segundo lugar, contra a distinção lógica proposta por Rickert. Este autor funda sua crítica ao realismo cognitivo no postulado da infinitude do mundo empírico desdobrado no tempo e no espaço, que seria inabarcável tanto intensiva quanto extensivamente. Esta tese, que Rickert expõe no início do seu trabalho de doutorado (1902, p. 31-47), permite-lhe também construir uma crítica do conhecimento concebido como uma cópia da realidade efetivamente dada. Afirma Rickert que qualquer parte do todo empírico é

\footnotetext{
${ }^{7}$ A sociologia da arte - da qual seriam exemplares os trabalhos sobre Michelangelo, Rembrandt e Rodin (F. DÖRRBACKES, 1995, p. 124-126) - também é reivindicada para sustentar essa tese. F. Dörr-Backes argumenta: "Com base no método interpretativo, Simmel elaborou uma peculiar epistemologia. As linhas mais importantes dessa epistemologia estavam já formuladas no estudo 'Os problemas da Filosofia da História', primeiramente publicado em 1892. A mais importante tese desse livro afirma que a realidade social deveria ser explicada não somente pelo pensamento racional, mas preferencialmente por uma combinação de pensamento racional e compreensão intuitiva. Para ilustrar essa reflexão, Simmel frequentemente comparava o cientista e o artista. Ele dizia que o artista, se ele fosse um bom artista, nunca pintava somente uma face ou uma paisagem tal como ela é. Antes ele tornava possível, para aquele que contempla o quadro, sentir o ambiente que envolve o objeto pintado. Para Simmel era absolutamente claro que tanto o artista quanto o cientista social, em sua procura pela 'natureza' das coisas, não poderiam usar somente fatos racionais, mas [teriam de usar] igualmente sentimentos e conhecimentos inconscientes e intuitivos. Somente pela condução conjunta de conhecimentos intuitivos e racionais eles poderiam mostrar-nos a essência de objetos, situações ou pessoas" (1995, p. 122). O fato de Simmel se distanciar dessa concepção do realismo científico que pressupõe uma cópia da realidade tal qual ela é - nos indica uma via de compreensão para a tese da autora de que Simmel procura combinar elementos do pensamento racional e da compreensão intuitiva. Mas os exemplos da arte, de maneira mais simples e mais acessível do que os enquadramentos da ciência, manifestam que há uma compreensão que surge justamente de uma composição de traços descontínuos, os quais captam traços de sentido e retratam motivos e significados que ficariam simplesmente "apagados" ou passariam despercebidos em uma reprodução pontual da realidade observada.
} 
inabarcável enquanto cópia exaustiva da realidade supostamente dada, uma vez que a infinitude intensiva do real impossibilita que o conceito se defronte com algum grau da realidade em que ela se apresente tal qual ela é. Ao comentar esse problema, Rickert põe em questão uma tese bastante controversa do próprio empirismo, ao afirmar:

se nossas ideias, para empregar a expressão de Hume, devem ser cópias de impressões, no sentido estrito da palavra, então estamos nós mais uma vez em face de uma tarefa insolúvel, por princípio, mesmo no tocante à mais ampla delimitação do terreno do conhecimento (RICKERT, 1902, p. $35)$.

Com esta observação, Rickert toca num ponto latente da avaliação epistemológica, que muito pouco se manifesta no exame da proposta empirista: de certo modo, conforme construída por Hume, a relação entre ideias e impressões encerra traços de uma teoria realista do conhecimento. Hume pressupõe que há um nível quantitativo ótimo para a apreensão subjetiva humana, além do qual se tornam incertos os campos de significação com os quais a linguagem opera ${ }^{8}$. Em Rickert, ao contrário, por mais insólita que pareça essa comparação - o conceito é sempre uma máquina a serviço de um escopo cognitivo, que permite às ciências recortar traços genéricos ou singulares da realidade e reordená-los em vista de intervenções cognitivas. Desse modo, a tese da infinitude intensiva e extensiva do mundo desdobrado no tempo e no espaço torna-se central para Rickert refletir sobre a relação entre a gradação dos escopos cognitivos e a teoria da formação de conceitos. Essa tese da infinitude intensiva e extensiva está na base da teoria da formação dos conceitos de Rickert (1902), conduzindo-o ao corolário de que toda teoria tem sua objetividade delimitada por seu recorte cognitivo. Desse modo, toda a apreensão cognitiva é validade por sua orientação teleológica, e não pelo fato de ser uma suposta cópia da realidade por ela designada. Embora não

\footnotetext{
${ }^{8}$ A teoria da linguagem, em Hume, está estreitamente conjugada com a proposta epistemológica do empirismo. Hume estabelece uma significação quase natural para os signos lingüísticos, uma vez que eles devem transportar ideias que são cópias das impressões. É claro que as ideias não podem ser cópias de um mundo externo diretamente dado à apreensão, mas correspondem, em contrapartida, ao mundo que é diretamente dado à percepção humana, ou seja, ao mundo que, através das operações da mente, se constitui no interior da subjetividade humana. Um dos principais temas da Introdução do Tratado da natureza humana (Hume, 2001, p. 19-24) é a posição de centralidade da ciência da natureza humana. A ela estão subordinadas todas as outras ciências, as quais dependem das ideias e impressões e das operações da mente para constituírem os objetos que podem estar no âmbito do interesse cognitivo do homem.
} 
nomeie Rickert, Simmel aponta justamente a insuficiência desta tese, ao afirmar:

\begin{abstract}
Assim, jamais é também explicitado suficientemente acerca dessa forma específica [de apreensão], que nenhuma ciência possa expressar de modo suficiente a complexidade e a plenitude intensivamente qualitativa da realidade efetiva (des wirklichen Daseins). Este ponto de vista quantitativo, que retorna, por fim, simplesmente a uma mera fraqueza da acuidade do nosso olhar ou da nossa capacidade, não supera ainda, por princípio, o naturalismo, e desconhece que a própria ciência histórica seria então algo diferente do mero espelhamento da realidade efetiva (als die Abspiegelung des Wirklichen), mesmo que fosse possível alcançá-la tecnicamente com plena precisão [...] (SIMMEL, 1997, IX: 280).
\end{abstract}

Simmel critica a distinção proposta por Rickert entre conceitos generalizantes e individualizantes, pois sustenta que não se trata somente de diferentes fins cognitivos. Se Simmel não aceita a distinção lógica proposta por Rickert, é porque sustenta que o conhecimento produzido pela história não é apenas seletivo ou fragmentário, mas também ontologicamente distinto do conhecimento produzido pelas ciências naturais. Assim como o conhecimento das ciências da natureza precisa apreender o mundo supostamente dado a partir da maneira pela qual a sensibilidade humana o projeta como mundo fenomenal, do mesmo modo o conhecimento das ciências históricas precisa apreender os fatos observáveis por meio da sequência construída a partir da experiência interior de um possível observador.

Este mesmo motivo, em terceiro lugar, é reapropriado na crítica a Dilthey ${ }^{9}$. Mas Dilthey, antes de Simmel, já tinha elaborado uma crítica bastante sistemática da posição realista, cindindo a experiência em duas esferas, uma interna e outra externa ao sujeito do conhecimento. Isto tornou a posição de Dilthey bastante peculiar, porque ela principia com uma separação ontológica dos domínios das ciências. Vejamos:

\footnotetext{
${ }^{9}$ É bastante difícil estabelecer a importância de Dilthey para Simmel. Uma interessante correlação entre os escritos e as vidas acadêmicas desses dois pensadores é apresentada por Helle (2001, p. 45-50). Mas julgamos que dois fatos básicos devam ser aqui mencionados. Do ponto de vista da diacronia, Simmel ingressou na Universidade de Berlin em 1876 , na qual Dilthey assumiu uma cátedra em 1882. Do ponto de vista epistemológico, é inevitável que a obra Die Probleme der Geschichtsphilosophie, publicada por Simmel em 1892, tenha sido considerada, por muitos de seus contemporâneos, uma alternativa aos fundamentos propostos em Einleitung in die Geisteswissenschaften, publicada por Dilthey em 1883 .
} 
As condições que procura a explicação mecânica da natureza explicam apenas um conteúdo parcial da realidade externa (der äusseren Wirklichkeit). Este mundo inteligível dos átomos, do éter, das vibrações é apenas uma abstração deliberada e sumamente artificial a partir do dado na vivência e na experiência (in Erlebnis und Erfahrung) (DILTHEY, 1959, p. 369).

A posição de Simmel seria incompreensível sem a posição de Dilthey, na medida em que Dilthey separa experiência externa e experiência interna, e toma essa segunda esfera da experiência, a vivência, como um fundamento da compreensão do mundo histórico. Mas não se trata simplesmente de repropor o argumento de que a compreensão do mundo histórico estaria fundada na vivência. Muito do esforço de Simmel está em pensar como a vivência pode se tornar acessível, para que disso possa se originar o fato da compreensão. Simmel afirma:

\footnotetext{
Não se pode descrever o singular, como ele existiu efetivamente (wie es wirklich war), porque não se pode descrever o todo. Uma ciência da totalidade do acontecer está excluída não apenas por causa de sua inabarcável quantidade, mas porque [essa ciência] estaria destituída de um ponto de vista [...] (1997, IX: 287).
}

Simmel pensa a vivência como uma totalidade que não pode ser penetrada completamente. Não se trata simplesmente de repropor o argumento de que o conhecimento humano seria fragmentário, mas sim de delimitar a vivência na medida em que ela constituiria uma totalidade que se tornaria impenetrável sem um critério seletivo. Simmel percebe o caráter irracional da vivência, porque ela é dotada de tal uma imediatidade, que ela não permite construir um fundamento de síntese para transformar a realidade apreendida em conhecimento histórico. Desse modo, se ela possibilita o acesso compreensível, ela é destituída do fundamento sintético que permite conferir uma unidade ao sentido dos dados observáveis. Simmel, em conseqüência, afirma que toda ciência terá de executar uma completa transformação da realidade (1997, IX: 280) e que o objetivo do historiador não é reproduzir o querer efetivo de um indivíduo, mas sim reconstruir este indivíduo como "um ser irreal (ein irreales Wesen)" (1997, IX: 281). Quando Simmel opõe o querer efetivo ao de "um ser irreal", quer justamente indicar a impossibilidade de se apreender a plenitude de qualquer vivência. Ao historiador cabe, portanto, 
reter somente os elos de uma certa vivência que permitiriam reconstruíla como se ela representasse a intencionalidade de um ator histórico. Por conseguinte, o historiador deve se afastar da imediatidade da vivência, para reconstruir o seu significado de modo racional e intencional, isto é, de tal modo que ela se torne uma ferramenta heurística nas mãos do historiador. Ou seja, Simmel, assim como Dilthey, se vale da reconstrução de estados psicológicos vividos por um ator histórico. Ao contrário de Dilthey, no entanto, Simmel pressupõe que esses fatos psíquicos também são artificiais e que eles nunca asseguram um acesso de fato ao que foi efetivamente vivido por outra pessoa. Este é o ponto que aproxima e distancia Dilthey e Simmel. Ambos os autores atribuem papel fundamental ao fato compreensivo, seja através da possibilidade da vivência, seja através da possibilidade de reprodução de estados psicológicos. No entanto, Simmel pressupõe que essa reprodução de estados psicológicos recobre seletivamente possíveis vivências de um outro agente histórico, sem nunca penetrar em sua vivência efetivamente. Essa reprodução é tratada, nesse sentido, como um recurso heurístico e não como um fundamento ontológico.

\section{A compreensão e o fundamento do conhecimento histórico 3.1 Estados hipotéticos de consciência como base da compreensão}

Simmel pode ser elencado entre os compreensivistas, mas sua tese é bastante singular. Simmel postula a história como um produto do substrato psíquico, cujo núcleo seria a personalidade enquanto fonte de uma apreensão individualizadora e unificadora dos fatos. Este é o início do enigma: estados subjetivos reconstruídos em uma subjetividade e que constituem a objetividade facultada à história (SIMMEL, 1997, IX: 265266). Se há cognição no campo da história, esta se cinge ao fato de representações reconstruídas poderem ser projetadas sobre atores e eventos, devendo, da reconstrução e da projeção, ser extraída a objetividade possível a tal atividade cognitiva. Simmel postula, portanto, que a objetividade no domínio da história é caracterizada pelo modo como o ator histórico faz migrar sua identidade para dentro da ação, conferindolhe unidade e sentido. 
É por este motivo que Simmel critica a posição do realismo ingênuo, uma vez que a história jamais pode ser vista como uma ciência descritiva de fatos ou ações humanas. Simmel indaga:

Mas o que significa esse compreender (dieses Verstehen) e quais são suas condições? A primeira delas é evidente, que aqueles atos conscientes sejam reproduzidos em nós, que nós possamos, como se diz, nos "transplantar na alma da outra pessoa" (SIMMEL, 1997, IX: 261-262).

Simmel toma a compreensão como o fundamento do conhecimento histórico. Por isso assinala a insuficiência do conceito de verdade como cópia descritiva da suposta realidade histórica, uma vez que não mais se trata de descrever seqüências de dados observáveis, mas de reproduzir os estados de consciência que tornariam um processo concebível. Simmel afirma que esta regra sintética somente pode ser apreendida a partir de uma unidade compreensiva, que tem sua origem quando o historiador consegue reproduzir em si os estados de consciência do ator histórico. Desse modo, observa:

Até agora, portanto, em qualquer recomposição [psicológica], a repetição (die Wiederholung) dos atos conscientes que se passaram em outro mostra-se vinculada com sua compreensão e indispensável para a mesma (SIMMEL, 1997, IX: 264).

A especificidade da história para Simmel é caracterizada por essa noção de compreensão, que pressupõe a capacidade de reconstituição dos estados de consciência de outrem. Compreender, no sentido aqui apontado, é ser capaz de conferir a um acontecimento o significado que outra consciência lhe atribuiria ${ }^{10}$. No entanto, não se trata aqui de penetrar na vivência de

\footnotetext{
${ }^{10}$ A utilização do método compreensivo torna também forçosa a reelaboração do conceito de verdade, uma vez que não mais se trata da correspondência entre conceitos e imagens sensíveis, mas da reconstrução de processos psíquicos que têm de tornar concebíveis as ações produzidas em um dado contexto histórico. Acerca disso, H. J. Helle comenta: "A questão pelos critérios da verdade, que conduziu Simmel à sua própria teoria pragmática da verdade, ocupa-o também como filósofo da história. Ele dirige-se ao historiador, do qual nos diz, de um modo que já nos é familiar, que ele reproduz algo de modo similar àquele como o pintor elabora uma obra de arte, na qual ele contempla e transforma criativamente a realidade, sem contudo fotografá-la. Pôr essa questão, de se o reproduzido pode ter a pretensão de ser verdade, não seria algo com sentido, se não houvesse a possibilidade de compreender. Para Simmel, portanto, o método do compreender (die Methode des Verstehens) é importante por causa disso, porque somente ele oferece em geral o pressuposto para que se possa checar o reconstruído conceitualmente em seu conteúdo de verdade" (2001, p. 90-91). Essa checagem do reconstruído não reconduz Simmel à tese do realismo cognitivo. Pelo contrário, seu significado principal é o de que uma, dentre as várias hipóteses possíveis a serem reconstruídas pelo historiador, possa ser lida de modo coerente a partir dos fatos observáveis. É desse modo que entendemos a referência de Helle a uma “teoria pragmática da verdade”. A reprodução de estados psíquicos, portanto, desempenha
} 
outrem - como pressupunha a proposta de Dilthey -, dado que esta constitui uma totalidade inabarcável, mas de reconstruir os estados de consciência de outrem a partir da minha própria vivência e no interior da minha consciência. Assim, o que em Dilthey constituía o que poderíamos chamar um fundamento real, em Simmel é considerado um pressuposto heurístico: o historiador, a partir da atualidade de sua vivência, tem a possibilidade de reproduzir em si supostos estados de consciência que teriam determinado a conduta de um ator histórico.

Mas, ao contrário de Dilthey, Simmel pressupõe uma incongruência entre as vivências e os estados psíquicos efetivos. Trata-se sempre de um método heurístico. É como se, através da reprodução de processos psíquicos, o historiador pudesse se pôr no lugar do outro, sem nunca poder saber efetivamente se as referências adotadas pelo outro são realmente as suas. Ou seja, aquele que compreende é sempre forçado a projetar sobre o outro a reprodução de estados de consciência que supostamente lhe pertenceriam. Simmel reconhece claramente este problema, ao afirmar:

\begin{abstract}
No entanto, subjaz uma dificuldade muito mais profunda, a saber, que os processos assim produzidos em mim mesmo não são, simultaneamente, os meus, que eu os pense historicamente, isto é, ainda que eu os represente e eles sejam, portanto, minhas representações, eu os penso como processos de um outro (1997, IX: 265).
\end{abstract}

Alicerçada no âmago do que assim considera o compreensivo, essa reconstituição de estados psíquicos é o que permite a Simmel inverter a proposta de Dilthey, uma vez que Simmel jamais considera que as vivências se interpenetrem. Elas são como mônadas, domínios fechados de experiências e sentimentos, mas que podem sustentar a intersubjetividade na medida em que são o suporte de atos compreensivos. Sem conceder tanto ao objeto como Dilthey, ou tudo tributar a uma distinção lógica como Rickert, Simmel centra sua crítica da razão histórica sobre essa forma cognitiva que se manifesta com a reprodução de estados psíquicos.

um duplo papel metodológico: de um lado, ela possibilita o acesso ao fato da compreensão, de outro, ela permite checar a adequação entre o que foi compreendido e sua inserção como fundamento das relações que podem ser constatadas entre os dados observáveis. Se a verdade for assim concebida, todo acontecimento histórico poderia conter várias possibilidades de significação, e todas poderiam ser apreendidas por processos psíquicos, que ofereceriam diversos ângulos para se examinar os sentidos de um tempo histórico. 


\title{
3.2 Compreensão e vivência
}

Uma questão que permitiria situar a posição de Simmel em relação a Dilthey seria a seguinte: o que este processo de reprodução de estados psíquicos concede à vivência? É perceptível em sua escrita o fato de que Simmel evita utilizar o conceito de vivência. No entanto, parece-nos que este conceito assedia o pensamento do autor. Isso fica patente, por exemplo, quando Simmel procura caracterizar o que singulariza o ato compreensivo. No intento de fazê-lo, afirma:

\begin{abstract}
Pois toda reprodução empática e toda compreensão (jedes Nachbilden und jedes Verstehen) de um objeto psicológico significa que aquele que compreende (der Verstehende) faz em si próprio justamente o percurso do processo anímico, em cujo conhecimento ele se afunda e no qual ele na medida em que o eu consiste no respectivo ato de representar-se - está efetivamente presente (wirklich ist) nesse momento (SIMMEL, 1997, IX: 299).
\end{abstract}

Como a consciência precisa tornar-se um campo de experimentos, aquilo que Dilthey concedia ao objeto, Simmel precisa conceder ao processo psíquico para poder fundamentar o ato compreensivo. Simmel entende que todo o processo de compreensão sempre ocorre no lócus do presente, porque aquele que compreende toma posição, naquele momento específico, em relação ao compreendido. Esse procedimento, contudo, afasta Simmel de uma apreensão direta do núcleo da vivência contido em um objeto de compreensão. Compreender e circunscrever um objeto de compreensão tornam-se, por conseguinte, atos vinculados pela posição presencial daquele que executa o ato de construir a significação de um possível objeto histórico.

Se Simmel menos concede que Dilthey ao objeto, a prova está em que pressupõe que a história acumulada no objeto tenha sua apreensão assegurada por padrões descontínuos. Ou seja, conquanto a compreensão sempre se exerça em meio a uma totalidade, ela sempre se efetiva parcialmente no interior de uma consciência. Desse modo, a objetividade vincular-se-ia à unidade que eu consigo reconstruir para tornar perceptível a presença de um objeto. Aqui o lócus do histórico já se torna multívoco, porque o que o objeto pode dar, a consciência precisa estar apta 
para receber. Essa multivocidade introduz forçosamente o problema da vivência na reflexão de Simmel, que pode ser retratado com as seguintes questões: o que pode ser reproduzido na vivência do cognoscente? A vivência precisa reproduzir algo para que haja compreensão? Em termos epistêmicos, esse problema poderia ser assim formulado: a objetividade em que medida depende da experiência vivida?

Essas questões evidenciam o quão conflituoso era o articulado por essa dobradiça entre compreensão e experiência vivida. Vejamos como Simmel articula esses dois conceitos, pondo em relevo, inclusive, a incongruência entre ambos. Simmel afirma:

O momento da vivência (Der Augenblick des Erlebens) empresta sentimentos significativos aos acontecimentos singulares, os quais a categoria da reflexão com frequência altera completamente. E de fato isso ocorre não apenas por causa da cegueira, ou seja, não apenas porque o presente, enquanto tal, costuma possuir um peso que se estende muito além de seu significado factual, mas porque para a vida enquanto vivenciada (für das gelebte Leben) estas coisas possuem uma importância que jamais possuem para a compreensão dessa vida (1997, IX: 279).

A referida incongruência é um componente muito importante na metodologia proposta por Simmel. Como recusa a vivência como núcleo da compreensão, Simmel procura, com esforço sempre atento, graduar a presença da vivência no interior do ato compreensivo. Desse modo, seu objetivo não é ir da Äusserung (exteriorização) ao Erlebnis (vivência) - o que intentava Dilthey -, mas sim explicitar como a reprodução de processos psíquicos dá origem a essas construções que chamamos história ${ }^{11}$. Poder-nos-íamos pensar ainda internados no itinerário de Dilthey, mas Simmel nos conduz a uma saída inusitada. A vivência não deixa de constituir a base do ato compreensivo, justamente porque permite a reprodução de atos psíquicos e sua conseqüente projeção sobre

\footnotetext{
${ }^{11}$ Estamos tentado chamar a atenção para o fato de que a tese de Dilthey opera com um pressuposto ontológico que representa um papel bem mais intenso do que aquele que pode representar em Simmel. Dilthey afirma, por exemplo: "Nesse ponto há uma relação bem mais favorável entre a realidade histórico-social e a inteligência. Para esta está dada imediatamente a unidade nela mesma, que é o elementar na composição todo-complexa da sociedade, enquanto esse mesmo [elemento] nas ciências da natureza precisa ser encontrado" (1959, p. 28). Em Dilthey há a imediatidade desse todo dado a essas unidades que ele denomina "indivíduos, todos psico-físicos" (1959, p. 29), e esse fato reunido com múltiplos recursos teóricos, é um dado básico da interpretação. A tese de Simmel não deixa de ter esse pressuposto ontológico presente em Dilthey, mas seu escopo é o de reter, em uma construção cognitiva artificial, uma compreensão vicária e mutilada, mas referenciada nos fatos observáveis.
} 
o ator histórico. Sua intensa imediatidade, em contrapartida, é o que traciona o passado para o lócus de minha experiência interna. Desse modo, é a vivência que confina o para onde o passado pode ser canalizado, internalizando-o em um receptáculo de forte poder axiológico. No constructo de Simmel é o passado que mergulha em mim, e não o contrário, somente quando as coisas passadas são acolhidas e reproduzidas por processos psíquicos é que elas podem ser dotadas de sentido e transformar-se naquilo que denominamos história. Por conseguinte, somente na medida em que o passado for acolhido pela atualidade daquele que compreende é que ele pode receber uma significação que configura sua dimensão histórica.

Este dispositivo permite a Simmel acomodar a vivência no quadro cognitivo, sem contudo abdicar da exigência de cientificidade. O mérito de Simmel está propriamente na disjunção que opera entre história e vivência. A história seria uma forma cognitiva, pois estaria interessada em reconstruir as cadeias significativas de um ser irreal, enquanto a experiência vivida confinaria um vínculo direto com a realidade, indicaria a imediatidade daquele que toma posição e compreende. Por isso a revivescência não é o que está em mira, quando é posto o objetivo de reconstituir estados psíquicos. O intentado é reproduzir estados psíquicos possíveis e não efetivos, ou seja, reproduzir não aqueles que foram efetivamente vividos pelo ator, mas aqueles que seriam estritamente facultados pelo contexto histórico como loci de intencionalidade. Para tanto, é necessário conseguir unificar tais estados e reproduzir a intencionalidade que os orienta, o que aqui se denomina compreender. Por outro lado, estes estados psíquicos possíveis somente podem ser reconstruídos a partir da experiência interna do historiador, que precisa reproduzi-los em si próprio e projetá-los sobre os atores históricos. Esta experiência interna constitui, portanto, esse grau da vivência que assedia a metodologia de Simmel. Repropondo então a crítica da razão histórica, Simmel (1997, IX: 291) afirma que as categorias operadas pelo historiador só podem apreender o que está sob a forma da experiência vivida, assim como, em Kant, o entendimento só cumpre sua função quando aplicado à sensibilidade.

Simmel nos traz um exemplo simples e lúcido do vínculo entre vivência e compreensão: a leitura de um livro. Simmel afirma: 
1088 | Veritas | Porto Alegre, v. 63, n. 3, set.-dez. 2018, p. 1073-1091

Caso eu, por exemplo, tenha interrompido a leitura de um livro e a retome outra vez após dias ou semanas, então se vincula em nós, sem lacuna, o agora lido com o lido outrora; o momento psicológico comporta a continuação dada por meio do conteúdo literário, como se todo o vivido e imaginado nesse ínterim não tivesse ficado interposto (SIMMEL, 1997, IX: 282).

Apesar das interrupções, a consciência é capaz de realinhar os trechos e dar sequência ao sentido, abstraindo as atividades que absorveram o leitor quando dos intervalos. Da mesma forma, o historiador deve operar com séries descontínuas para poder extrair padrões significativos que esclareçam certa conduta política ou certa sequência de pinturas ou tal conjunto de escritos. Nesse sentido, Simmel assinala constantemente essa incongruência entre vivência e compreensão: não é preciso acesso ao todo da vivência para que a compreensão se efetive, a vivência sempre efetiva parcialmente a atualidade do sujeito que constrói e projeta sentidos. Ao contrário de Dilthey, em Simmel a vivência é sempre propriedade particular daquele que compreende, ou seja, o indivíduo não é dotado de uma totalidade compreensiva, mas é constituído por um ponto de gerado pela atualidade daquele que compreende. A compreensão, por conseguinte, não penetra na vivência sedimentada no objeto, mas traz o objeto para o interior da minha vivência, onde ele é reconstruído idealmente pelos sentidos que consigo reproduzir a partir da minha própria vivência.

Proporções guardadas, aqui temos o modo de Simmel traçar o que denominaríamos um tipo ideal. Tomando por exemplo uma decisão política, Simmel nos diz que o objetivo do historiador é o de construir “[...] para seus fins um ente irreal: o suporte de ações políticas, cuja continuidade existencial passa por cima de todos aqueles elos [psicológicos vividos] intermediários, como se eles não fossem existentes” (SIMMEL, 1997, IX: 281). Notemos apenas que, neste caso, o tipo ideal configura sempre um estado psíquico possível, erigido sobre uma síntese enraizada na experiência vivida. A história, nesse modelo, sempre surge quando a armação de tal tipo ideal é possível. Um estado psíquico idealizado então conforma o quadro compreensivo, dentro do qual se estabelece um acesso objetivo às possibilidades significativas que singularizam uma época ${ }^{12}$.

${ }^{12}$ Transportando esse problema para o quadro da filosofia kantiana, P.-U. Merz-Benz faz o seguinte comentário: "Conhecer o acontecimento histórico com auxílio da ciência, e na verdade - como exigido - em todas as suas relações 
Sem a construção de tais possibilidades, eu posso ser atravessado por muitos pensamentos e sentimentos difusos, sem jamais alcançar uma forma cognitiva. O historiador, ao reproduzir processos psíquicos objetiváveis, individualiza formas objetivas de intelecção e modela padrões significativos, mediando o acesso a um hipotético mas objetivável tempo histórico. Sem tal mediação, o distanciamento compreensivo jamais ocorreria, porque o sujeito cognoscente permaneceria imerso e disperso na imediatez de sua própria experiência vivida. O combatente de Maratona, por exemplo, viveu extraordinárias experiências, não indispensáveis para a compreensão da batalha. Vivência, aliás, considerada por Simmel inacessível, pois deveras é a própria experiência vivida do historiador que lhe faculta a construção de estados psíquicos com os quais uma época se torna compreensível.

\section{Conclusão}

Colocamos como meta de Simmel expor como da vivência se originam essas construções que chamamos história. E elas surgem dessas unificações idealizadas de estados psíquicos, com os quais o historiador constrói uma compreensão objetiva de certas individualidades e as situa como uma das possibilidades do tempo histórico.

Para ressaltar a peculiaridade dessas construções, procuramos mostrar, inicialmente, como o pensamento de Simmel pode ser separado de três vertentes cognitivas: do realismo ingênuo, que pressupunha o conhecimento como cópia da realidade; do perspectivismo de Rickert, fundado em uma distinção lógica; e da teoria compreensiva de Dilthey, erigida completamente sobre a penetração em um núcleo de experiências vividas. Para destacar a contribuição singular de Simmel nesse debate, tentamos mostrar como ele se apropria da inter-relação entre vivência e

\footnotetext{
efetivas singulares e concretas [que se estabelecem] entre processos psíquicos e acontecimentos externos, é para Simmel, por isso, nada além do que a expressão de uma tarefa infinita, de uma ideia kantiana” (MERZ-BENZ, 1995, p. 15). Essa comparação é bastante sugestiva, porque permite compreender bem a distância - nem sempre bem demarcada - que há entre Simmel e Dilthey. Conquanto aquele que compreende, para fazê-lo, precise reconstruir internamente processos psíquicos, essa reconstrução é obtida por um procedimento típico-ideal. São selecionados traços psíquicos que irão compor o núcleo compreensivo, mas Simmel jamais opera com o pressuposto de que esse núcleo compreensivo possa ser idêntico à vivência de um certo agente histórico. Por isso é propícia a comparação com Kant, porque as possibilidades de significação de um tempo histórico permanecem como um arquétipo, do qual os indivíduos singulares e concretos podem se aproximar por vários ângulos e perspectivas, sem nunca apreendê-lo plenamente ou em sua suposta real tessitura.
} 
ato psíquico ao tratá-la como um recurso heurístico. Desse modo, aquele que compreende acolhe em sua consciência os atos idos, procura conferirlhes sentido e unidade a partir da sua vivência, e, por fim, projeta essa construção idealizada sobre o ator histórico, para conferir as possibilidades de interpretação que podem ser produzidas por esse procedimento heurístico.

A importância e a fecundidade desse recurso epistemológico, proposto por Simmel, está em que não precisamos supor que aquele que compreende tem que penetrar em uma vivência integralmente ou objetivamente sedimentada no objeto, pois aquele que compreende não precisa penetrar no querer efetivo de outro indivíduo, mas apenas recolhêlo dentro de sua vivência. Esta opera como suporte compreensível, para que aquele que compreende possa se projetar no interior de outra sequência de atos psíquicos. A compreensão, portanto, é uma construção irreal que deve ser utilizada como um recurso heurístico, possibilitando ao investigador interpretar e apreender seletivamente os sentidos com os quais os agentes históricos dotaram suas ações.

\section{Referências}

DILTHEY, Wilhelm. Einleitung in die Geisteswissenschaften. Versuch einer Grundlegung für das Studium der Gesellschaft und der Gechichte. In: Gesammelte Schriften. 7. unv. Aufl. Stuttgart: Teubner; Göttingen: Vanderhoeck \& Ruprecht, 1959 .

Introducción a las ciencias del espíritu. Traducción de Julián Marias. Madrid: Alianza, 1980.

DÖRR-BACKES, Felicitas. The Study of Culture in Georg Simmel's Writings on Art. In: ; NIEDER, Ludwig. (eds.). Georg Simmel between modernity and postmodernity / Georg Simmel zwischen Moderne und Postmoderne. Würzburg: Königshausen und Neumann, 1995. p. 119-128.

HELLE, Horst Jürgen. Georg Simmel: Einführung in seine Theorie und Methode / Georg Simmel: Introduction to his Theory and Method. [edição bilíngüe]. München; Wien: Oldenburg, 2001.

HUME, David. Tratado da natureza humana: uma tentativa de introduzir o método experimental de raciocínio nos assuntos morais. Tradução de Déborah Danowski. São Paulo: Editora UNESP / Imprensa Oficial do Estado, 2001. 
KANT, Immanuel. Kritik der reinen Vernunft. Nach der 1. und 2. Orig.-Ausg. Hrsg. von Raymond Schmidt. 3. Aufl. Hamburg: Meiner, 1990.

. Crítica da razão pura. Tradução de Valerio Rohden e Udo Baldur Moosburger. 3. ed. São Paulo: Nova Cultural, 1987.

LICHTBLAU, Klaus. Causality or Interaction? Simmel, Weber and Interpretive Sociology. [Source: Theory, Culture \& Society, 1991, vol. 8, p. 33-62]. In: FRISBY, David (ed.). George Simmel. Critical Assessments. London u. a.: Routledge, 1994. v. II. p. 6184 .

MERZ-BENZ, Peter-Ulrich. Gesetzeswissenschaft und erzählende Wissenschaft - Der Wissenschaftsdualismus bei Georg Simmel. In: DÖRR-BACKES, Felicitas; NIEDER, Ludwig. (eds.). Georg Simmel between modernity and postmodernity / Georg Simmel zwischen Moderne und Postmoderne. Würzburg: Königshausen und Neumann, 1995. p. 05-21.

RICKERT, Heinrich. Die Grenzen der naturwissenschaftlichen Begriffsbildung. Eine logische Einleitung in die historischen Wissenschaften. Tübingen und Leipzig: Mohr, 1902.

. Kulturwissenschaft und Naturwissenschaft. [Der Text der vorliegenden Ausgabe folgt [...] [die] sechste und siebente duchgesehene und ergänzte Auflage]. Stuttgart: Philipp Reclam Jun., 1986.

. Ciencia cultural y ciencia natural. Traducción por Manuel G. Morente. Madrid: Calpe, 1922.

SIMMEL, Georg. Die Probleme der Geschichtsphilosophie: Eine erkenntnistheoretische Studie. In: . Gesamtausgabe. Frankfurt am Main: Suhrkamp, 1997. Bd. IX. p. 227-419.

. Les problèmes de la philosophie de l'histoire. Introduccion et traduction de l'allemand par Raymond Boudon. Paris: PUF, 1984.

SCHWARTZ, Barry. How is history possible? Georg Simmel on empathy and realism. Journal of Classical Sociology, 2017, v. 17, n. 3, p. 213-237. 